\section{Hiperplasia adrenal congênita: estudo qualitativo sobre definição e redefinição sexual, cirurgia de dilatação e apoio psicológico (parte II)}

\author{
Congenital adrenal hyperplasia: a qualitative study on sex definition \\ and redesignation dilation surgery and psychological support (part II)
}

Mariana Telles-Silveira', Vânia F. Tonetto-Fernandes ${ }^{1,2}$,

Paulo Schiller ${ }^{3}$, Claudio E. Kater ${ }^{1}$

\section{RESUMO}

Objetivo: Identificar questões relacionadas à definição e redesignação sexual e à cirurgia corretiva em pacientes com hiperplasia adrenal congênita $(\mathrm{HAC})$ e compreender a inserção do psicólogo no seu atendimento. Métodos: Selecionaram-se 21 sujeitos: 7 especialistas de cinco instituições do Sistema Único de Saúde (SUS), 9 familiares e 6 pacientes com HAC, seguindose padrões da pesquisa qualitativa. Neste artigo, analisaram-se três das categorias estudadas: "definição e redesignação sexual", "cirurgia e dilatação" e "psicologia". Resultadlos: A situação de indefinição sexual é a que mais angustia os pais, enquanto a redesignação inquieta mais os médicos. A sensação de isolamento para lidar com a doença e tratamento foi comum nas pacientes; os procedimentos de dilatação foram sua principal queixa. Os médicos acham que a cirurgia deve ser feita com brevidade para evitar traumas posteriores. Conclusões: Diante de questões psicológicas complexas, chama a atenção o fato de que nem todo serviço de atendimento especializado conta com a presença de um psicólogo. Os exames de dilatação causam traumas nas pacientes. No grupo estudado, constataram-se dificuldades para lidar com as questões relacionadas à sexualidade. Arq Bras Endocrinol Metab. 2009;53(9):1125-36

Descritores

Hiperplasia adrenal congênita; anomalias de diferenciação sexual; definição sexual; redesignação sexual; cirurgia reconstrutiva; psicologia; psicanálise

\footnotetext{
ABSTRACT

Objective: To identify relevant questions related to sex definition and re-designation and reconstructive surgery in patients with congenital adrenal hyperplasia (CAH), and to understand the role of the psychologist in providing care for these patients. Methods: We selected 21 subjects: 7 pediatric endocrinologists from 5 Brazilian Public Health System institutions, 9 parents and 6 patients with $\mathrm{CAH}$, according to a qualitative research model. In this paper, 3 of the studied categories are analyzed: "sex definition and re-designation", "reconstructive surgery/ vaginal dilation", and "psychology". Results: Parents' main anguish relates to the situation of an unnamed sex at birth, whereas sex re-designation was distressful to physicians. A sense of loneliness when dealing with the disease and treatment was a common anguish among patients; dilation procedures were the major complaint. In general, physicians recommend that genital reconstructive surgery be performed early on to avoid future trauma. Conclusions: In such a complex scenario, it is remarkable that not all the reference service staff have a psychologist on duty. Difficulties to deal with questions involving sexuality were evident and dilation procedures are an additional source of trauma for these patients. Arq Bras Endocrinol Metab. 2009;53(9):1125-36

Disciplina de Endocrinologia, Departamento de Medicina, Universidade Federal de São Paulo (Unifesp), São Paulo, SP, Brasil ${ }^{2}$ Hospital Infantil Darcy Vargas, São Paulo, SP, Brasil ${ }^{3}$ Departamento de Pediatria da Unifesp, Hospital e Maternidade São Luiz, São Paulo, SP, Brasil

Correspondência para:

Claudio E. Kater

Disciplina de Endocrinologia, Departamento de Medicina Unifesp

Rua Pedro de Toledo, 781, $13^{\circ}$ andar 04039-032 - São Paulo, SP, Brasil kater@unifesp.br

Recebido em 16/Fev/2009 Aceito em 5/Ago/2009 


\section{INTRODUÇÃO}

A s anomalias de diferenciação sexual (ADS) (1) e a Adefinição do sexo vêm sendo entendidas, historicamente, como uma urgência médica. Essas anomalias receberam várias denominações em diferentes momentos históricos, mostrando as diversas visões sobre o mesmo assunto (2). Em particular, chama a atenção um importante movimento de 1920: a "era cirúrgica", conhecida pela ideia de que o sexo deveria ser estabelecido pelo clínico e construído pelo cirurgião. Recomendava-se aos médicos que diagnosticassem um único sexo e que ajudassem a eliminar as características incompatíveis com o sexo diagnosticado.

Esse paradigma baseou-se nas ideias de John Money $(3,4)$, da Universidade Johns Hopkins, em Baltimore, Estados Unidos, que criou conceitos importantes para ampliar o modo de tratar essas crianças. Em 1955, criou a ideia sobre "papel de gênero" e o conceito de que todas as crianças nascem com uma "neutralidade psicossexual", o que permitiria designá-las em qualquer gênero, desde que a anatomia do genital conferisse credibilidade à conduta a ser indicada.

Nessa época, a participação dos pais era praticamente nula. Eles não participavam das decisões e eram orientados a evitar toda e qualquer situação de ambiguidade com seus filhos. Tais condutas foram estabelecidas e consideradas eficientes por 40 anos, mas, atualmente, vêm sendo contestadas por pacientes (5), médicos e psicólogos.

Extensas pesquisas sobre a influência hormonal começaram a despontar como determinantes do comportamento e identidade de gênero em pacientes com ADS, supondo que o recém-nascido tem uma predisposição biológica a construir uma identidade de gênero, influenciada por fatores sociais posteriores (1,6-10). Além disso, fatores religiosos e relacionados ao desejo dos pais também parecem influenciar a formação da identidade de gênero.

Diante de controvérsias clínicas, teóricas e contradições entre o que é dito pelo médico e pelos pacientes e/ou familiares, o presente trabalho procurou compreender o cenário de atendimento desses pacientes, no intuito de identificar as angústias, as dúvidas e as ansiedades dos pacientes e seus pais, bem como da equipe médica que os assiste.

Em publicação anterior (11), foram discutidos os seguintes aspectos: 1 . Doença e tratamento; 2 . Dúvidas e angústias e 3 . Relacionamentos. No presente artigo, serão abordadas as questões relevantes relacionadas à definição e redesignação sexual, à cirurgia corretiva e à compreensão do papel do psicólogo no atendimento de pacientes portadores de hiperplasia adrenal congênita (HAC) por deficiência de 2l-hidroxilase (D21OH) (12-14) em sua forma clássica, que constitui uma das causas mais comuns de ADS.

\section{DESENHO DA PESQUISA E METODOLOGIA}

\section{Sujeitos e procedimentos}

O presente estudo teve como referencial a metodologia qualitativa (15-22), realizada a partir de um roteiro semiestruturado de entrevistas, conforme descrito em detalhes em publicação anterior (11).

Em resumo, foram entrevistados 21 sujeitos: 8 mães, com idades entre 24 e 37 anos, e 1 pai de 41 anos, de 9 pacientes $(2 \mathrm{M} / 7 \mathrm{~F})$ com idades entre 3 meses e 17 anos, além de 6 pacientes com HAC (forma clássica da $\mathrm{D} 21 \mathrm{OH}$ ) com idades entre 17 e 42 anos, todas do sexo feminino, e 7 médicos especialistas (endocrinopediatras) de seis centros de referência do Sistema Único de Saúde (SUS) do Estado de São Paulo (pertencentes a cinco instituições), designadas como centros A, B, C, D, E e F.

Todos os entrevistados, antes de conceder a entrevista, assinaram um termo de consentimento livre e esclarecido, permitindo que houvesse gravação e transcrição. O termo de consentimento foi avaliado e aprovado pelos dois Comitês de Ética em Pesquisa, dos centros D e F.

\section{Análise dos dados}

A análise consistiu em interpretar os dados, levantar hipóteses e redefinir questões relevantes, conforme descrito detalhadamente em publicação anterior (11).

Ao final da análise, as entrevistas foram condensadas em matrizes (2l) para que os três conjuntos de sujeitos (familiares, pacientes e médicos) fossem estudados e comparados. O uso das matrizes permitiu a triangulação (18) dos dados, que serão posteriormente discutidos.

Para cada conjunto de sujeitos entrevistados, foram criadas seis categorias analíticas (Matriz A) que foram exploradas e detalhadamente estudadas (Tabela 1).

Em publicação anterior, foram discutidas as três primeiras categorias e, no presente artigo, serão discutidas as demais: "Definição e redesignação sexual", "Cirurgia e dilatação" e "Psicologia." 


\begin{tabular}{|c|c|c|c|}
\hline & Familiares $(n=9)$ & Pacientes $(n=6)$ & Médicos $(n=7)$ \\
\hline 1 & Doença e tratamento & Doença e tratamento & $\begin{array}{l}\text { Doença e tratamento } \\
\text { Número de casos atendidos }\end{array}$ \\
\hline 2 & Dúvidas e angústias & Dúvidas e angústias & $\begin{array}{l}\text { Dúvidas e angústias } \\
\text { Quais as perguntas mais comuns feitas pelos pais e } \\
\text { pacientes }\end{array}$ \\
\hline 3 & Como avalia a sua relação com o médico & $\begin{array}{l}\text { Como avalia sua relação com o médico e com os } \\
\text { pais }\end{array}$ & Como avalia sua relação com o paciente e os pais \\
\hline 4 & $\begin{array}{l}\text { Como lidou com a definição sexual } \\
\text { Reação específica do pai } \\
\text { Primeira internação }\end{array}$ & Contemplado nos itens 1,2 e 5 & 0 que pensa sobre a redesignação sexual \\
\hline 5 & Cirurgia & $\begin{array}{l}\text { Cirurgia/dilatação } \\
\text { Relação com o corpo }\end{array}$ & Idade preferencial para indicar a cirurgia \\
\hline 6 & Como e quando procuram o serviço de psicologia & Como e quando procuram o serviço de psicologia & $\begin{array}{l}\text { Como e quando encaminham casos para avaliação } \\
\text { psicológica } \\
\text { Relacionamento com outras equipes }\end{array}$ \\
\hline
\end{tabular}

\section{RESULTADOS}

Em relação à Categoria 4: "Definição e redesignação sexual", foram encontrados:

\section{Familiares}

Ao relatarem a internação, os pais das meninas reafirmaram sobre o suspense e a angústia da indefinição sexual (11). Não sabiam o que dizer para os familiares e amigos que vinham à maternidade e não sabiam o que pensar sobre o assunto.

Cinco dos familiares tiveram seus filhos internados na Unidade de Terapia Intensiva (UTI) por desidratação. A relação entre UTI e morte foi feita por todos esses pais: "Unidade de Tratamento Intensivo, está na UTI? A gente pensa que se está lá é porque não volta; quem fica na UTI é porque o próximo passo é morrer”.

As duas mães de meninos contaram histórias semelhantes: como os filhos não nasceram com genitália ambígua, voltaram para casa e em 15 dias não ganharam peso e começaram a ter crises de desidratação. Os dois meninos foram e voltaram de alguns hospitais até que um pediatra suspeitasse de HAC e os internasse na UTI devido ao seu mau estado geral.

O pai entrevistado deu um relato do que comumente se chama de luto antecipado do bebê $(23,24)$. A literatura psicanalítica descreve o fenômeno do luto antecipado dizendo que os pais de bebês com doenças muito graves utilizam como defesa, diante da angústia de morte, o afastamento dos bebês, evitando contato físico (carinhos, abraços etc.) e psicológico (não supõem um sujeito no bebê). Também se pode constatar uma mudança na estrutura familiar: sua esposa permaneceu no hospital por três meses, o pai perdeu o emprego e teve de assumir as tarefas domésticas: "Foi tenso o começo. A gente achou que seria uma semana e foram três meses. Você vem para consulta e cada vez ela estava pior. Eu trouxe uma criança teoricamente saudável e, quando eu a olhava no berço, via uma caveirinha; eu nem queria me apegar".

Para a mãe 6, a internação foi um momento de confrontar o desejo de que seu bebê fosse um menino com a informação de que se tratava de uma menina. A interação com a equipe, nesse momento, ficou tensa e a mãe demonstrou ter muitas dúvidas sobre a escolha do médico. Mesmo acompanhando passo a passo os exames e a proposta de tratamento, parecia paralisada diante da possibilidade de ter uma menina. Em seu relato, constatou-se que isso permanece no discurso da mãe até os dias de hoje, interferindo na educação da filha e fomentando dúvidas quanto à feminilidade da criança. O médico informou que, na infância, essa criança apresentou "tomboismo" (padrão de comportamento masculino em meninas) e difícil controle hormonal.

Em geral, o tempo de espera para a realização do registro foi de 45 a 60 dias. As mães que tinham como informação do pré-natal que o bebê era uma menina lidaram aparentemente melhor com o fato de o bebê permanecer no sexo feminino, mesmo com a alteração da genitália.

Uma das mães viveu a experiência da definição sexual como uma troca de bebês na maternidade. Durante a gestação, o ultrassom indicava um menino, portanto todo o enxoval era azul. A escolha do nome do 
bebê expressava a ambiguidade vivida; os pais incluíram uma parte do nome de menino originalmente esperado, transformando-o em feminino: "Eu falo para o meu marido: parece que nasceram duas, uma não tem mais, tenho uma só. Não sei se é uma sensação de perda, mas sei lá se trocou, sabe quando erram o filho? Troca na maternidade e falam: toma que esse é o seu”!

Duas mães parecem não ter aceitado a definição sexual e, de certa forma, permaneceram duvidosas quanto à decisão do médico. No relato de ambas fica claro que elas não participaram da escolha do sexo, sendo espectadoras das decisões médicas. O desejo de ter o menino anunciado não foi acolhido por ninguém da equipe que acompanhou essas mães; pode-se constatar em seus relatos que elas não elaboraram a escolha do sexo. Ambas permaneciam com dúvidas sobre as filhas serem verdadeiramente mulheres, identificando traços masculinos nelas. Curiosamente, uma das pacientes apresentou "tomboismo" na infância e mantém péssimos controle hormonal e aderência ao tratamento, enquanto a outra tem bom controle hormonal e acompanha regularmente o ambulatório: "Eu achei que era homem, depois falaram que era menina com problema. Eu fiquei muito triste, porque com 6 meses ela já tinha cabelo na vagina; era feio. O outro sexo eles arrancaram porque ela é menina. Hoje ela tem um ombro largo de homem e diz que gosta de mulher".

Algumas mães aproveitaram a entrevista para falar como sentiram falta da presença dos maridos nas consultas, queixando-se do distanciamento que eles tinham do tratamento dos filhos. Outras, ao contrário, apontaram a importância do apoio emocional dado pelo marido no momento do nascimento; diziam estar extremamente fragilizadas e que puderam encontrar conforto na promessa do marido de que tudo acabaria bem.

Assim como elas, os maridos também gostariam de saber por que seus filhos nasceram daquele jeito. Alguns pareciam, segundo o relato das mães, não aceitar o fato e chegavam a duvidar da paternidade: "Ele começou a beber. Ele não aceitava; ele olhava para ela e dizia: eu não fiz isso! No começo ele dizia: é um menino! Pra que isso? Ele dizia que en estava inventando doença”.

\section{Médicos}

Sobre a questão da redesignação sexual, todos os médicos concordam que é uma situação angustiante, complexa e difícil de lidar. Em todos os serviços, mesmo naqueles em que não há um psicólogo ou psiquiatra na equipe, a avaliação lhes parece fundamental e necessária quando estão diante de um caso desses. Alguns chegam a citar que é esse profissional que deve orientar a equipe sobre como abordar o assunto com os pais.

Dois dos médicos apontam para as divergências existentes nas equipes nessas situações, o que pode gerar alguma iatrogenia para o paciente, que acaba sendo atendido por vários especialistas. Um deles descreve isso como uma fragmentação do paciente, assinalando que muitas vezes o que está em jogo é a vaidade do especialista. É muito comum, de acordo com esse profissional, que ninguém consiga decidir quem é a referência para o paciente, o que o deixaria mais confuso e sozinho: Existem algumas vezes fogueiras de vaidades $\mathrm{em}$ cima disso; determinadas pessoas batem o pé achando que tem que ser de um jeito ou de outro e as decisões não são necessariamente unânimes”.

Outro diz que não há equipe que possa dar conta do sofrimento dos pais numa situação como essa. Todos parecem concordar que, uma vez estabelecido o sexo social ou psicológico, a alternativa da mudança de sexo torna-se bastante remota. Para eles, crianças de até 2 ou 3 anos de idade podem ser redesignadas quanto ao sexo, mas depois disso só com a avaliação do sexo social e psicológico. Em exceção, outro médico afirma que o endocrinologista não pode perpetuar o erro que foi cometido na maternidade e que, independentemente do sexo de criação da criança, é preciso fazer o diagnóstico correto e propor uma redefinição do sexo, o que deve ser entendido como uma definição correta.

Há um consenso em relação aos casos em que o sexo social já está estabelecido, nos quais, portanto, não se pode optar pela redesignação. Isso implicaria, no caso de uma menina criada como menino, ser submetida a uma mutilação dos órgãos internos (útero e ovários), o que, para todos, apesar do consenso, parece ser algo muito desconfortável, uma vez que a criança poderia ter vantagens em permanecer no seu sexo genético, já que supostamente poderia menstruar e ter filhos.

\section{Categoria 5: "Cirurgia e dilatação"}

\section{Familiares}

Dos nove entrevistados, dois tinham meninos que não precisaram de cirurgia; duas mães relataram que as filhas ainda não haviam sido operadas, uma delas porque a filha nasceu com uma pequena alteração da genitália, o que fazia os médicos acreditarem que, só quando ela fosse mais velha, poderiam avaliar a necessidade de in- 
tervenção. A outra disse que o médico desejava operá-la antes de completar um ano.

Para uma das mães, a cirurgia foi encarada inicialmente como uma mutilação, uma mutilação do filho que ela insistia em ter (mesmo que em fantasia), mas a equipe médica afirmava ser uma menina. Mesmo com todos os exames feitos e a clínica avaliada de que seu bebê era uma menina, a mãe, por dois anos, recusou-se a aceitar o fato e continuou a vestir a filha de menino, desmarcando a cirurgia agendada pela equipe médica. Sua ambiguidade era tamanha que a mãe resolveu consentir a cirurgia num impulso, sem preparo prévio e sem o consentimento do pai. Hoje, reavaliando, diz que ainda tem dúvidas sobre a filha ser mesmo uma menina; consegue perceber que ela é vaidosa e feminina, mas acredita que tenha permitido que tirassem algo dela (um pênis) e que não tem ideia do que isso pode significar em sua vida. Manteve, durante toda a espera da cirurgia, a esperança de que os médicos encontrariam órgãos sexuais masculinos e sua filha, então, voltaria a ser seu bebê imaginário.

Outra mãe também expressou a fantasia de que a filha foi mutilada. A criança estava com 4 anos à época da cirurgia, de acordo com a mãe. Ela relata que a filha entrou numa fila "interminável" para realizar a cirurgia e que foi muito difícil suportar ver a genitália malformada, descrita pela mãe como feia, nojenta e cheia de pelos.

O relato do pai é um reflexo de que os significados dos procedimentos médicos são interpretados de forma única pelos pais. Embora incomodado, como todas as outras mães, com a malformação da filha, inclusive enfrentando problemas semelhantes aos acima relatados, este pai preferiu adiar a cirurgia da filha com a seguinte justificativa: manter-se o mais longe possível da internação. A experiência anterior de quatro meses de internação da criança foi vivida pelo pai e sua família como algo traumático; assim, ao ouvir falar da cirurgia, associavam imediatamente com a internação e por isso não conseguiam sequer imaginar consentir e marcar a cirurgia. Outro aspecto relevante é que esse pai se sentia acolhido pela equipe que o atendia dizendo que eles lhe deram um tempo para que pudesse se preparar para a cirurgia: "Operar fazia a gente ter que pensar em hospital. Quando falavam pra gente em operar, entrava na nossa mente internar e então era assim: falavam uma coisa e chegava outra."

\section{Pacientes}

As seis pacientes entrevistadas nasceram com algum grau de alteração na genitália (graus 3-4 da classificação de
Prader) e já tinham feito a correção cirúrgica (genitoplastia) no momento da entrevista. Cinco delas precisaram de mais de uma cirurgia; em geral, a primeira foi realizada na infância (entre 2 e 3 anos) e a segunda, na adolescência. A sexta paciente foi operada apenas aos 28 anos; esta paciente relatou que sabia que tinha algo estranho em sua genitália, mas não sabia dizer ao certo o que era. Como nem seus pais nem os médicos que a atendiam falavam sobre o assunto, só ficou sabendo da correção da vagina no serviço de endocrinologia de adultos. Para essa paciente, a cirurgia foi como um marco. A partir de então ela referiu que se sentia mais feminina, que a cirurgia havia lhe dado a oportunidade de menstruar como as outras mulheres e que isso a fez refletir sobre a possibilidade de ser mãe e ter uma relação sexual, algo que, até então, parecia ser um assunto impensado.

Outra paciente expressou sua angústia por nunca ter conversado com ninguém sobre a cirurgia e em relação aos exames pós-cirúrgicos. Comenta que sabia que tinha algo de "errado" com ela, mas não sabia o que era e que só conseguiu perceber alguma diferença depois da cirurgia. Relata suas sessões de dilatação como rituais de tortura, descrevendo o cenário dos procedimentos como se ainda estivesse dentro dele. Durante a entrevista, emocionou-se ao lembrar-se desses fatos e disse sentir-se aliviada por poder falar com alguém sobre isso: "Foi horrivel. Não gosto de me lembrar, eu não me sentia à vontade".

A paciente 5 , diferentemente das outras, precisou fazer uma cirurgia de colostomia antes de realizar a cirurgia da genitália (o intestino fica interrompido e o paciente excreta suas fezes numa bolsa presa à barriga). A experiência do uso da colostomia durante a adolescência foi o que mais marcou essa paciente; ela relata a vergonha por precisar ir à escola com a bolsa coletora de fezes na barriga. Ela se lembra de como se sentia vulnerável por não poder controlar o momento da defecação ou eliminação de gases, dizendo que a parte da genitália nem foi o mais difícil e o que mais a incomodava era não ter controle sobre o próprio corpo. Quanto à dilatação, comenta que sabia de sua necessidade para que não perdesse a cirurgia. No entanto, assume que não fez como foi pedido pelo médico, justificando sua não adesão ao fato de que, na época, nem pensava em ter relações sexuais e, por isso, não achava necessário fazer esse procedimento, que era visto por ela como dolorido e incômodo.

Cabe ressaltar que, em alguns dos centros de atendimento avaliados, o procedimento de dilatação não tem 
sido mais usado rotineiramente ou, quando necessário, é feito sob anestesia.

Duas das seis pacientes estudadas referiam relacionamento estável, uma delas com atividade sexual frequente e a outra com dificuldades ao coito. Uma delas nunca havia tido namorado e as outras três não tinham relacionamento fixo e se disseram homossexuais.

\section{Médicos}

Três dos médicos disseram que, em seu serviço, a cirurgia ocorre por volta dos 2 anos de idade ou com a retirada das fraldas. Um deles diz que gostaria que a cirurgia fosse feita mais precocemente, mas respeita a opinião do cirurgião: "Ele é quem decide a parte técnica".

Os outros quatro disseram que a cirurgia acontece o mais precocemente possível. Em geral ocorre até 1 ano de idade, dependendo da avaliação do urologista ou cirurgião pediátrico e das vagas no centro cirúrgico.

\section{Categoria 6: "Serviço de psicologia"}

\section{Familiares}

Duas das mães entrevistadas nunca haviam conversado com um psicólogo até o momento da entrevista. Uma delas somente o fez por ocasião da pesquisa de mestrado desse profissional; além disso, aponta o fato de a filha ser muito fechada e não gostar de falar com outras pessoas.

Outra mãe recebeu o encaminhamento para procurar o serviço de psicologia, mas não deu continuidade às sessões por causa de todos os outros tratamentos médicos aos quais a filha era submetida (o que nos faz pensar que o psicólogo, nesse serviço, entraria como mais uma subespecialidade e não alguém integrado à equipe).

A mãe 4 procurou uma psicóloga por indicação da médica em razão de um sintoma da filha (medo de dormir sozinha); como não havia outra queixa, fez algumas sessões e não deu continuidade ao acompanhamento.

Já a mãe 5 conversou com uma psicóloga durante a internação e espera pelo diagnóstico, mas não se lembrava do nome da profissional que a atendeu. Refere que o psicólogo é necessário para fazer uma interlocução entre a família e os médicos, justificando essa ideia pelo fato de que nem sempre encontrava tempo na consulta médica para tirar suas dúvidas.

A mãe 6 refere-se à dificuldade em dividir o que pensava a respeito dos exames a que sua filha foi submetida, dizendo como se sentia sozinha e sem ninguém para falar sobre seus medos e angústias. Acredita que a falta de continuidade de profissionais na área da psicologia seja um fator para abalar sua confiança neles, além de afirmar que falar sobre esse assunto é algo muito difícil.

A mãe 8 e o pai trouxeram uma leitura diferente do profissional da psicologia: ambos mencionaram a importância de ter um profissional como esse inserido na equipe que atende seus filhos. A mãe 8 relata que a filha estava sentindo muita angústia diante da iminente cirurgia a qual se submeteria e, por isso, achava importante passar pelo psicólogo para que ela pudesse falar sobre os pesadelos que tinha. Além disso, acreditava que a filha tinha de lidar com questões diferentes das vividas pelas meninas de sua faixa etária, tais como puberdade precoce e dificuldade escolar. De alguma forma, essa mãe pôde explorar a escuta do psicólogo para tratar de questões que extrapolavam o tratamento médico de sua filha.

O pai entrevistado afirma que a presença de um profissional dessa área possibilita que a criança seja vista além da sua doença; é um profissional que se preocupa em ouvir os problemas dos pais e da criança, problemas que muitas vezes podem ser invisíveis, como ele diz, como os traumas. Segundo seu relato, o psicólogo asseguraria sua posição de sujeito, cheio de dúvidas, angústias, perguntas e questionamentos: "Quando a gente chegou aqui em São Paulo achou que a médica fosse daquele tipo que só dá receita, mas não, aqui analisa, faz perguntas, exames e indica a psicóloga para conversar”.

\section{Pacientes}

Somente uma das entrevistadas foi avaliada por um psicólogo durante todo o tratamento. A idade da avaliação foi 14 anos, antes da correção cirúrgica. De acordo com a paciente, ela não se beneficiou do atendimento psicológico, pois se sentia fechada e tímida.

Três delas manifestaram interesse em ter alguém com quem conversar sobre o tratamento, sobre suas dúvidas e angústias. De certa forma, aproveitaram a entrevista para expor alguns conflitos vividos durante vários momentos da vida. Falar sobre o assunto foi visto por elas como um alívio: "Eu nunca conversei com ninguém e sentia muita vontade de falar, porque precisava colocar isso pra fora. Quando vou falando, isso me alivia, porque eu não tenho coragem de falar pra mais ninguém sobre isso. Isso é muito vergonhoso, passar pelo que eu passei, isso não se fala pra ninguém e ficar guardando isso é muito ruim". 


\section{Médicos}

Todos os médicos relatam que o endocrinologista é a referência para o paciente portador de HAC. Quatro deles contam com equipe interdisciplinar para trabalhar com os pacientes e suas famílias. Têm como rotina um encontro mensal multidisciplinar para a discussão de casos clínicos. Um deles salienta que possui um grupo de apoio a pais e pacientes e que participa de uma consulta interdisciplinar para discutir mais detalhadamente os casos de difícil controle.

Três médicos trabalham somente com endocrinologistas (residentes, pós-graduandos, estagiários, além de alunos). A falta de equipe interdisciplinar é vista por um deles como uma dificuldade no trabalho, uma vez que é perceptível que a comunicação torna-se escassa e, muitas vezes, falha entre os profissionais. Em geral, os outros profissionais (geneticistas, psicólogos, "radiologistas", cirurgiões e assistentes sociais) são contatados por interconsulta.

Já outro acredita que os casos de HAC deveriam ser atendidos por uma equipe de ultraespecialistas com contato permanente. Como não conta com essa equipe, prefere trabalhar sozinho.

Quatro dos médicos entrevistados contam com um psicólogo em seu serviço. Os psicólogos que trabalham com dois deles somente prestam assistência aos casos mais graves ou de redesignação de sexo, pois o serviço de psicologia não consegue atender toda a demanda. Já para outro, o psicólogo é o maior vínculo dos pacientes e, por isso, o atendimento médico e psicológico é interligado desde o início do tratamento. Um terceiro aponta para a própria dificuldade em escutar as angústias dos pais e, por esse motivo, tenta encaminhar todos os pacientes para o psicólogo. Admite que parece haver "um pacto entre eles", no qual: "Já que não suporto ouvir a angústia deles, eles, por sua vez, não me perguntam e vão perguntar para o psicólogo".

Os demais não contam com um psicólogo no grupo, mas dois deles pedem interconsulta quando sentem necessidade, enquanto o outro prefere não encaminhar.

\section{DISCUSSÃO}

Como em artigo anterior (11), a discussão consistiu na triangulação dos dados encontrados nos três grupos de sujeitos (familiares, pacientes e médicos). A Matriz B descreve resumidamente os dados encontrados nos grupos de sujeitos (Tabela 2 ).

A inclusão de definição sexual com redesignação sexual numa mesma matriz poderia ser motivo de questionamento, pois se trata de termos distintos que falam sobre definição do sexo em contextos muito diferentes, um ao nascimento e o outro ao longo da vida. Na redesignação sexual, o sexo da criança precisará ser modificado, se for possível, ou seja, existe um sexo que, por algum motivo, foi definido de forma inadequada.

Mas, ao ler as respostas dadas pelos familiares e médicos, foi encontrada uma correspondência entre as duas situações. Ou seja, o momento de indefinição sexual é o que mais angustiou os pais; em contrapartida, a situação de redesignação sexual é a que mais angustiou os médicos. De certa forma, o modo de descrever as

\begin{tabular}{|c|c|c|}
\hline $\begin{array}{l}\text { Como lidaram com a definição sexual. Reação específica do } \\
\text { pai. Primeira internação }\end{array}$ & $\begin{array}{l}\text { Contemplado nos } \\
\text { itens } 1,2 \text { e } 5\end{array}$ & 0 que pensa sobre a redesignação sexual \\
\hline Familiares & Pacientes & Médicos \\
\hline \multirow{3}{*}{$\begin{array}{l}0 \text { tempo de espera para o registro foi de } 45 \text { a } 60 \text { dias } \\
\text { Os que tinham como informação pré-natal que o bebê era uma menina } \\
\text { lidaram melhor com a permanência no sexo feminino }\end{array}$} & & A situação de redesignação sexual foi vista por todos como a mais \\
\hline & & angustiante, complexa e difícil de lidar \\
\hline & & Alguns acreditam que nenhuma equipe é capaz de apaziguar o sofrimento \\
\hline \multirow{2}{*}{$\begin{array}{l}\text { Desejar um menino ou ter essa informação pelo ultrassom dificultou a } \\
\text { aceitação da mãe }\end{array}$} & & dos pais numa situação como essa \\
\hline & & A avaliação do psiquiatra ou psicólogo nessa situação é indispensável \\
\hline \multirow{2}{*}{$\begin{array}{l}0 \text { conflito inicial estava centrado em como explicar a situação para } \\
\text { parentes e amigos }\end{array}$} & & Momento de muitas divergências entre as equipes \\
\hline & & Risco de iatrogenia: "0 paciente é de todos e não é de ninguém" \\
\hline $\begin{array}{l}\text { Ouvir que o bebê era hermafrodita ou tinha os dois sexos também } \\
\text { dificultou a aceitação sobre a escolha do sexo }\end{array}$ & & Uma vez estabelecido o sexo social, a mudança de sexo é muito remota \\
\hline \multicolumn{3}{|l|}{0 risco de morte tornou o problema da definição sexual secundário } \\
\hline \multicolumn{3}{|l|}{$\begin{array}{l}\text { As crises de perda de sal e as internações deixaram sequelas no } \\
\text { comportamento dos pais (insegurança, medo) }\end{array}$} \\
\hline \multicolumn{3}{|l|}{0 luto antecipado do bebê foi relatado } \\
\hline \multicolumn{3}{|l|}{ Alguns pais chegaram a duvidar da paternidade } \\
\hline Alguns temiam que as filhas sofressem preconceito & & \\
\hline
\end{tabular}


situações, mesmo sendo tão distintas, tinha certa semelhança, uma vez que tanto um como o outro estavam diante de um fenômeno irrepresentável. Assim, mesmo que não intencionalmente, essas duas situações acabaram ficando lado a lado.

Além disso, a situação de ambiguidade de ambos os momentos fez que o bebê ou a criança, diante dos pais e dos médicos, ficasse em suspenso, à espera de uma definição, de um nome. Mengarelli (25) sustenta que: "Se por ambiguo entendemos aquilo que se presta a vários sentidose, por conseqüência, a um sentido incerto, a genitália, sendo ambigua, impede, suspende o acolbimento da criança como menino ou menina. As letras a e o e toda a série de objetos derivativos da vigência de uma destas letras (cor de roupa, tipo de brinquedo, detalhe de acessórios, etc.) ficam suspensas".

Ou seja, em ambas as situações não se sabia como se referir ao bebê ou à criança, o que provocava uma série de sentimentos similares, tanto nos médicos quanto nos pais.

Portanto, a primeira internação foi, para esses pais, um marco, um momento vivido com muita angústia e ansiedade, descrito por muitos deles como uma situação que não tem nas palavras uma forma de representação: "Onde já se viu uma criança nascer com sexo indefinido? Fazer exame para descobrir quem ele é?”, disseram as mães que foram ouvidas nesse trabalho. Relatam que o sexo ao nascimento não pode ser nomeado e, portanto, passa do estatuto natural para o estatuto de diagnóstico (Matriz C) (Tabela 3).

O momento da realização da cirurgia foi um tema sobre o qual a maioria dos médicos pareceu concordar. Todos, de certa forma, são da opinião de que, quanto mais cedo fizer, melhor será.

Para os familiares, a cirurgia foi um momento esperado e, ao mesmo tempo, temido e definitivo. A cirurgia apareceu como a única possibilidade de confirmação do diagnóstico de que as meninas eram realmente meninas. Essa aparente redundância nos remete ao fato de que os órgãos femininos encontram-se escondidos, internos e não podem ser visualizados pelos pais. Assim, o que eles viam correspondia ao sexo oposto, masculino. As mães que tinham a certeza e o desejo de que suas filhas fossem meninas viam na cirurgia a possibilidade de que isso se efetivasse e de que suas filhas se tornassem meninas de verdade. Por outro lado, as mães que desejavam um menino ficaram na sala de espera aguardando fantasiosamente ouvir do médico: "abrimos a barriga da sua criança e encontramos os testículos!”. Como isso não aconteceu, acreditavam que os médicos mutilaram suas filhas.
As pacientes viram a cirurgia como um procedimento necessário; para algumas delas, a cirurgia permitiu que se sentissem mais mulheres, ou uma mulher como as outras. A maioria não foi informada sobre a cirurgia antecipadamente e ficou extremamente ansiosa com isso; somente uma delas recebeu a informação prévia da mãe e relatou se sentir muito bem por isso.

Dúvidas em relação ao próprio corpo e ao modo como se sentem apareceram intimamente relacionadas à cirurgia e aos procedimentos de dilatação. $\mathrm{O}$ modo como essas mulheres foram tocadas, olhadas e examinadas trouxe uma alteração na autoimagem delas: "Não me sinto mulher como as outras, só me senti mulher quando perdi as formas masculinas; me senti mulher depois da cirurgia e comecei a me cuidar mais".

Os procedimentos de dilatação foram apontados como os mais doloridos e desconfortáveis. Para algumas mães e pacientes, esse foi um momento traumático do tratamento; não sabiam como lidar com a situação e optaram pelo silêncio para se defender.

Mengarelli (25) diz que o corpo é um lugar de inscrição do discurso dos pais a seu respeito, evocador de semelhanças, da linhagem familiar, das origens da sexuação (conceito psicanalítico que trata sobre a percepção da diferença entre masculino e feminino). Quando ninguém se pergunta além da função comprometida sobre quem é essa criança, ela fica seriamente comprometida na possibilidade de vir a se constituir subjetivamente.

Em seu livro "Intersexo, una clinica de la ambiguidadad sexual", Goralli (26) descreve que tais pacientes são vistos pela medicina como um problema a ser resolvido. O trabalho dessa autora está voltado para a compreensão do que se passa com esse sujeito que recebe, ao nascer, vários discursos. Coloca em evidência a necessidade de ouvir o que esses pacientes têm a dizer, defendendo a ideia de que a sexualidade está em jogo e precisa ser vista com cuidado. A autora revela que muitos médicos e pais não suportam a ansiedade diante de tal quadro e veem na cirurgia a única saída para sanar o problema.

Vários especialistas que trabalham em associações de pacientes com ADS, como a Intersex Society of North America (ISNA) (5), têm reivindicado novas normas de atendimento para o tratamento de crianças que nascem com malformação genital, que foram criadas a partir da experiência vivida pelos próprios pacientes. Eles afirmam que ao recém-nascido deve ser designado um sexo, pois reconhecem que nossa sociedade é estruturada biologicamente e que as cirurgias precoces deveriam 
Tabela 3. Matriz C - Cirurgia e dilatação

\begin{tabular}{lll}
\hline Cirurgia e dilatação & Cirurgia e dilatação: relação com o corpo & Idade preferencial para indicar a cirurgia corretiva \\
\hline Familiares & Pacientes & Médicos \\
\hline Duas ainda não tinham passado pela cirurgia: uma & Todas já tinham feito a correção cirúrgica & Todos recomendam que a cirurgia ocorra por volta dos \\
ansiava pela cirurgia e a outra não & A maioria precisou de mais de uma correção & 2 anos (talvez antes) ou com a retirada das fraldas \\
Em geral as mães se sentiram sozinhas e angustiadas & Com exceção de uma delas, todas fizeram a & Alguns dependem da avaliação do cirurgião e da \\
no dia da cirurgia & primeira cirurgia na infância & disponibilidade de vagas cirúrgicas \\
Duas mães acharam que as filhas foram mutiladas & Não falar com os pais nem com profissionais sobre & \\
Mesmo após a cirurgia, duas mães mantiveram-se & a cirurgia foi um fator de ansiedade para muitas & \\
ambíguas em relação ao sexo da criança & delas & \\
0 único pai associou cirurgia à internação e disse não & Dilatação: procedimento doloroso, invasivo, & \\
estar preparado para passar por isso & traumático. Mesmo sabendo os motivos para sua & \\
& realização, muitas disseram que prefeririam não 0 & \\
& ter feito \\
& A cirurgia e o tratamento tiveram relação direta com & \\
& a construção da autoimagem & \\
& A identidade parece influenciada substancialmente & \\
& pela forma como foram olhadas e tocadas pelos & \\
& médicos e por seus pais & \\
& Os efeitos dos hormônios masculinos tiveram uma & \\
& ação direta sobre a construção da feminilidade & \\
& A alteração da genitália faz com que elas se sintam \\
& diferentes das outras mulheres \\
\hline
\end{tabular}

ser suspensas até o momento que o próprio paciente pudesse falar sobre o que pensa sobre isso. Sugerem, também, que na equipe de trabalho exista um profissional especializado e habilitado para escutar o que os pacientes têm a dizer (27).

Creighton e Liao (28) afirmam que os procedimentos cirúrgicos são criticados do ponto de vista ético, social e clínico. Sendo esse um debate emotivo e angustiante tanto para os pacientes e seus pais como para os clínicos, acreditam que muitos itens devam ser considerados antes de se sugerir a cirurgia, apontando, como razões para operar:

- desenvolvimento mais estável da identidade de gênero;

- um melhor resultado psicossexual e psicossocial;

- alívio da ansiedade dos pais.

$\mathrm{E}$, como razões para não operar:

- complicações decorrentes da cirurgia em pacientes adultas, entre elas: infecções urinárias recorrentes, fístulas, dor no clitóris, incontinência, estreitamento uretral e estenoses.

Em seu trabalho, as mulheres com HAC que tinham sido operadas referiram menos atividade sexual que as demais. Muitas mulheres precisaram de mais tratamentos para a vagina antes da puberdade, incluindo novas vaginoplastias. A cirurgia do clitóris afetou a função sexual de algumas das pacientes entrevistadas. Por- tanto, cada caso deve ser visto com cuidado, levando-se em conta as várias questões envolvidas (Tabela 4).

Dos sete médicos entrevistados, quatro disseram contar com o apoio de um psicólogo em seu serviço. Entre eles, somente dois incluem a consulta psicológica como parte do fluxograma de atendimento dos familiares que chegam ao serviço. Em geral, o psicólogo é contatado via interconsulta nos casos que são considerados mais graves ou de difícil controle. Dessa forma, o psicólogo é mais um entre os vários especialistas que os pais terão de consultar.

A falta de uma equipe coesa foi apontada por alguns médicos como um fator complicador para a compreensão de todos os aspectos do caso. A fragmentação de condutas e as divergências de opiniões foram identificadas pelos médicos como um agravante para o bom andamento do caso. Discussões clínicas eram realizadas somente em três serviços de referência.

Um dos médicos comentou que conta com um psicólogo em seu grupo de trabalho e que, além desse profissional, conta com uma assistente social que conhece a maioria dos casos. Eles participam mensalmente, junto com o serviço de urologia, de um grupo de pais, além de realizarem uma consulta em que todos os profissionais estão presentes e discutem os casos.

Apesar da realidade constatada, encontrou-se no discurso dos pais o reconhecimento do psicólogo como 


\begin{tabular}{|c|c|c|}
\hline $\begin{array}{l}\text { Como e quando procuram o serviço de } \\
\text { psicologia }\end{array}$ & $\begin{array}{l}\text { Como e quando procuram o serviço de } \\
\text { psicologia }\end{array}$ & $\begin{array}{l}\text { Como e quando encaminham casos para } \\
\text { avaliação psicológica. Relacionamento com } \\
\text { outras equipes }\end{array}$ \\
\hline Familiares & Pacientes & Médicos \\
\hline $\begin{array}{l}\text { Duas nunca haviam conversado com um psicólogo } \\
\text { Uma recebeu encaminhamento, mas não deu } \\
\text { continuidade } \\
0 \text { psicólogo foi visto como aquele que pode fazer uma } \\
\text { interlocução entre os pais e os médicos } \\
\text { A rotatividade do profissional de psicologia nos } \\
\text { serviços parece abalar a confiança das mães nesse } \\
\text { profissional } \\
\text { Uma mãe e um pai disseram que esse profissional é } \\
\text { essencial para ouvir suas angústias, medos e } \\
\text { ansiedades, tornando-os mais seguros sobre o que } \\
\text { pensam e sentem }\end{array}$ & $\begin{array}{l}\text { Apenas uma foi avaliada por psicólogo e achou muito } \\
\text { ruim o tratamento } \\
\text { Três manifestaram interesse em ter alguém para } \\
\text { conversar sobre o tratamento, dúvidas e angústias } \\
\text { Todas aproveitaram a entrevista para falar sobre o que } \\
\text { sentiam } \\
\text { Falar sobre as questões não trouxe mais angústia para } \\
\text { elas }\end{array}$ & $\begin{array}{l}\text { Quatro contam com um psicólogo no seu serviço } \\
\text { Para alguns, o psicólogo é chamado somente nos } \\
\text { casos mais graves } \\
\text { Três não contam com esse profissional: dois deles } \\
\text { pedem uma interconsulta quando necessário e o } \\
\text { outro não encaminha por falta de um profissional } \\
\text { especialista em seu serviço } \\
\text { O endocrinologista é a referência para os pacientes } \\
\text { com hiperplasia adrenal congênita } \\
\text { Quatro fazem encontros mensais para discussão de } \\
\text { casos com a equipe multidisciplinar } \\
\text { Uma possui um grupo de apoio e realiza consulta em } \\
\text { conjunto com outros profissionais em seu serviço } \\
\text { Três só trabalham com endocrinologistas } \\
\text { A falta de equipe multidisciplinar é vista como uma } \\
\text { dificuldade no trabalho } \\
\text { Uma acha que esse tipo de paciente só deveria ser } \\
\text { tratado por ultraespecialistas }\end{array}$ \\
\hline
\end{tabular}

alguém que pode ouvi-los, tratar de sintomas não médicos, como medos e angústias, além de garantir um olhar para outros aspectos do desenvolvimento da criança, e não só a doença.

Embora médicos e pacientes achem que falar sobre o assunto possa aumentá-lo, tanto os familiares quanto as próprias pacientes parecem ter se beneficiado do ato de falar. Os médicos, por sua vez, pareciam não gostar de estender a conversa com os pais ou diziam não saber lidar com o que eles colocavam: "Eu acho que quanto mais a gente fala, mais o problema aumenta, então prefiro falar poucas coisas com os pais; se falar muito, eles entram em depressão".

Algumas das pacientes acreditavam que não falar sobre o assunto pouparia seus pais de sofrer e reviver o que eles sentiram no dia de seu nascimento. No entanto, falar com um psicólogo não trouxe nenhum desses conflitos e, pelo que muitas afirmaram, possibilitou alívio para algumas questões traumáticas, bem como a possibilidade de dar um sentido para essas experiências vividas.

Chama a atenção o fato de que muitos dos entrevistados não tiveram nenhum contato com um psicólogo durante todo o tratamento. Além disso, os que tiveram não encontraram um psicólogo com formação e conhecimento na área, o que o tornou apenas mais um entre os profissionais que assistiram a criança.

Mesmo considerando a escassez de contato com esse profissional, o psicólogo foi visto como aquele que pode ser o interlocutor entre eles e o médico, alguém capaz de traduzir as questões e facilitar a comunicação entre eles. Para todos, o psicólogo é aquele que pode ouvir a respeito de seus sentimentos.

Alguns dos textos consultados na literatura $(1,5,29$ 31) apontam o fato de que o apoio psicológico deve ser permanente não só para os pais mas também para as crianças e que aos pacientes deve ser revelado seu tratamento conforme seu desenvolvimento psicológico, ajustando a linguagem ao seu nível cognitivo. Além disso, um trabalho com os médicos também parece ser importante.

Munõz (5) atesta que a falta de informações claras para o paciente durante todo o processo de tratamento parece ser especialmente traumática. Ele assegura que isso leva muitos pacientes a pensarem que têm males muito piores ou que são monstruosos. Muitos se sentem estigmatizados, envergonhados, tristes e, inclusive, têm a sensação de terem sido vítimas de abuso sexual. Quando esses pacientes chegam a conhecer (ou a intuir) a verdade, diz o autor, manifestam uma grande frustração, raiva e, muitas vezes, rompem com suas famílias e abandonam o tratamento. Ele afirma que é o psicólogo quem deve orientar os médicos e pais para prover recursos para os pacientes compreenderem sua própria condição.

Neste trabalho, pôde-se notar que as pacientes sabiam sobre o tratamento, sobre como haviam nascido. Algumas delas se sentiam diferentes, mas não monstruosas. Uma delas sentia que tinha sido vítima 
de uma tortura durante o procedimento de dilatação. $\mathrm{E}$ as outras se sentiam bem e resolvidas com o próprio tratamento; uma delas inclusive se casou e contou para o marido a respeito do tratamento. Mesmo que indiretamente informadas, não verbalizaram raiva sobre a própria condição nem raiva dos pais. Pelo contrário, foi encontrado um ato amoroso na tentativa de poupar os pais de mais sofrimento.

\section{CONCLUSÕES}

Ao realizar as entrevistas, ficou evidente que esses pais se sentiam mais solitários e angustiados quando não podiam falar sobre suas hipóteses, dúvidas e fantasias. Ouvir suas histórias parece ser um modo de incluí-los no tratamento, em especial quanto ao sexo desejado.

Uma interpretação possível seria a de que as hipóteses pessoais verbalizadas por pacientes e pais deveriam ser abolidas e reorientadas e, então, preenchidas por exposições mais claras e precisas sobre o que é a doença, mas, ao fazê-lo, estaria se incorrendo no mesmo erro: supor que não há um saber nesses sujeitos e que não devemos ouvi-los.

Todos os sujeitos entrevistados afirmaram que há algo que não se pode dizer, que existe um tema que não pode ser conversado e se pensou ser o tabu da sexualidade. Isso faz com que se acredite que uma medida de trabalho nessa vertente seja necessária.

Diante da complexidade de aspectos psicológicos tão evidentes nessa doença, chamou-se a atenção que, apesar de o psicólogo ser reconhecido como o profissional capaz de realizar a interlocução entre a família e o campo médico, ele não está presente em todos os serviços de referência, o que se faz pensar que se está deixando de lado aspectos fundamentais do tratamento dessas crianças.

Não foi possível ouvir outros pais (homens) de pacientes, exceto um único que compõe a presente amostra. Não foram ouvidos também pacientes homens, o que se permite questionar se eles, mesmo não nascendo com genitália ambígua, não teriam questões próprias para discutir sobre o tratamento. Além desses, não foram ouvidos urologistas pediátricos (ou cirurgiões infantis).

Agradecimentos: aos médicos especialistas que gentilmente participaram da pesquisa e que, por motivo de sigilo, não puderam ser mencionados publicamente; aos pais e pacientes que deram seu testemunho durante a pesquisa; ao Hospital Infantil Darcy Vargas e aos integrantes do Grupo Vida que foram fonte inspiradora deste trabalho, e aos colegas do Ambulatório de Adrenal da Escola Paulista de Medicina da Universidade Federal de São Paulo (Unifesp-EPM).

Declaração: os autores declaram não haver conflitos de interesse científico neste estudo.

\section{REFERÊNCIAS}

1. Lee PA, Houk CP, Ahmed F, Hughes IA. Consensus statement on management of intersex disorders. Pediatrics. 2006;118(2):488-500.

2. Spinola-Castro AM. A importância dos aspectos éticos e psicológicos na abordagem do intersexo. Arq Bras Endocrinol Metab. 2005;49(1):46-59.

3. Money J, Hampson JG, Hampson JL. Hermaphroditism: recommendations concerning assigment of sex, change of sex, and psychologic management. Bull Johns Hopkins Hosp. 1955;97(4):284-300.

4. Money J, Ehrhardt AA. Man and woman, boy and girl: the differentiation and dimorphism of gender identity from conception to maturity. Baltimore:The Johns Hopkins University Press; 1972.

5. Munõz EC. Case 1 Part III: Los estados intersexuales y los tratamientos médicos dominantes. Acesso em: 29 de julho de 2008. Disponível em: http://www.isna.org/node/34

6. Meyer-Bahlburg HFL, Dolezal C, Baker SW, Carlson AD, Obeid JS, New MI. Prenatal androgenization affects gender-related behavior but not gender identity in 5-12-year-old girls with congenital adrenal hyperplasia. Arch Sex Behav. 2004;33(2):97-104.

7. Meyer-Bahlburg HFL. Introduction: gender dysphoria and gender change in persons with intersexuality. Arch Sex Behav. 2005;34(4):371-3.

8. Meyer-Bahlburg HFL, Dolezal C, Baker SW, Ehrhardt AA, New MI. Gender development in women with congenital adrenal hyperplasia as a function of disorder severity. Arch Sex Behav. 2006;35(6):667-84.

9. Hines M, Brook C, Conway GS. Androgen and psychosexual development: core gender identity, sexual orientation, and recalled childhood gender role behavior in women and men with congenital adrenal hyperplasia. J Sex Res. 2004;41(1):75-81.

10. Hall CM, Jones JA, Meyer-Bahlburg HFL, Dolezal C, Coleman M, Foster $\mathrm{P}$, et al. Behavioral and physical masculinization are related to genotype in girls with congenital adrenal hyperplasia. J Clin Endocrinol Metab. 2004;89(1):419-24.

11. Telles-Silveira M, Tonetto-Fernandes VF, Schiller P, Kater CE. Hiperplasia adrenal congênita: estudo qualitativo sobre doença $e$ tratamento, dúvidas, angústias e relacionamentos (parte I). Arq Bras Endocrinol Metab. 2009;53(9):1112-24.

12. Therrel BL. Newborn screening for congenital adrenal hyperplasia. Endocrinol Metab Clin North Am. 2001;30(10):15-30.

13. Lemos-Marini SHV, Mello MP. Hiperplasia congênita das suprarenais (HCSR) In: Guerra Junior G, Guerra ATM, eds. Menino ou menina? Os distúrbios da diferenciação do sexo. São Paulo: Manole; 2002. p. 61-87.

14. Tonetto-Fernandes VF, Barbosa FAC, Kater CE. Hiperplasia adrenal congênita. In: Chacra AR, editor. Guias de medicina ambulatorial e hospitalar da Unifesp-EPM endocrinologia $1^{\text {a }}$ ed. São Paulo: Manole; 2009. p. 203-18.

15. Turato ER. Tratado da metodologia de pesquisa clínico-qualitativa. Petrópolis: Vozes; 2003.

16. Blay S. Desenhos de pesquisa. Disciplina Metodologia de Pesquisa Qualitativa, Departamento de psiquiatria da Unifesp (comunicação pessoal); 2007.

17. Mays N, Pope C. Rigour and qualitative research. Br Med J. 1995;8:311(6997):109-12. 
18. Pope C, Mays N. Reaching the parts other methods cannot reach: an introduction to qualitative methods in health and health services research. Br Med J. 1995;311:42-5.

19. Pope C, Ziebland S, Mays N. Qualitative research in health care analyzing qualitative data. Br Med J. 2000;320:114-6.

20. Patton MQ. Qualitative evaluation and research methods. Newbury Park: Sage; 1990. p. 169-86.

21. Britten N. Qualitative interviews in medical research. Br Med J. 1995;311:251-3.

22. Miles MB, Huberman AM. Qualitative data analysis. Thousand Oaks: Sage; 1994. p. 277-82.

23. Brun D. A criança dada por morta. São Paulo: Casa do psicólogo; 1996.

24. Mercer VR. Volte para casa e desmanche o quartinho. O luto perinatal. In: Bernardino LMF, Rohenkohl CMF, editores. O bebê e a modernidade: abordagens teórico-clínicas. São Paulo: Casa do psicólogo; 2002. p. 205-18.

25. Mengarelli JK. Genitália ambígua e ambigüidade do desejo. $1^{\circ}$ ensaio. In: Amarelinhas - Biblioteca Freudiana de Curitiba. 1994; p. 56-63.
26. Goralli V. Intersexo, una clinica de la ambiguidadad sexual. Buenos Aires: Grama; 2007.

27. Diamond M, Sigmundson HK. Management of intersexuality: Guidelines for dealing with persons with ambiguous genitalia. Arch Ped Adolesc Med. 1997;151:1046-50.

28. Creighton SM, Liao LM. Changing attitudes to sex assignment in intersex. BJU Int. 2004;93(5):659-64.

29. Ferrari VRB. Anomalias da diferenciação sexual: aspectos psicológicos. In: Setian N, editor. Endocrinologia pediátrica - aspectos físicos e metabólicos do recém-nascido ao adolescente. São Paulo: Sarvier, $2^{a}$ ed; 2002. p. 465-72.

30. Damiani D, Guerra-Junior G. As novas definições e classificações dos estados intersexuais: o que o Consenso de Chicago contribui para o estado da arte? Arq Bras Endocrinol Metab. 2007;51(6):1013-7.

31. Ansermet F. Clínica da origem - A criança entre a medicina e a psicanálise. Rio de Janeiro: Contracapa; 2003. 